\title{
Areal distribution of the oxygen-isotope ratio in Antarctica: comparison of results based on field and remotely sensed data
}

\author{
H. Jay Zwally, ${ }^{1}$ Mario Giovinetto, ${ }^{2}$ Mike Graven, ${ }^{3}$ Vin Morgan, ${ }^{3}$ Ian Goodwin ${ }^{4}$ \\ ${ }^{1}$ NASA/Goddard Space Flight Center, Code 971, Greenbelt, MD 20771, U.S.A. \\ ${ }^{2}$ Earth Sciences 356, University of Calgary, Calgary, Alberta T2N 1N4, Canada \\ ${ }^{3}$ Antartic CRC and Australian Antartic Division, Box 252-80, Hobart, Tasmania 7001, Australia \\ ${ }^{4}$ Antarctic CRC and SCAR-GLOCHANT Project Office, Box 252C, Hobart, Tasmania 7001, Australia
}

\begin{abstract}
An updated compilation of oxygen-isotope ratio data for 562 sites in Antarctica shows a significant increase in the number of sites and an improvement in the representation of the coastal zone over previous versions. The data base consists of ratio values $\left(\delta^{18} \mathrm{O}\right.$; multi-year mean ${ }^{18} \mathrm{O} /{ }^{16} \mathrm{O}$ relative to Standard Mean Ocean Water, in \%o) compiled as the dependent variable, together with data for the so-called independent variables: latitude, surface elevation, mean annual surface temperature and mean annual shortest distance to open ocean denoted by the $20 \%$ sea-ice concentration boundary. The problem of covariation between so-called independent variables is minimized using stepwise regression analyses. A general model is described using all the field data, and the regional variation at drainage-system scale is assessed by contrasting models for two physiographically distinct regions. In addition, entity-specific models are determined using data subsets for the conterminous grounded-ice and ice-shelf areas. Inversions of the specific models are applied to a $100 \mathrm{~km}$ grid data base to produce two contoured distributions of the ratio, one based on field data, and the other on remotely sensed data. The difference between these produces residuals that, relative to the summation of standard errors of the models, are small in most of the interior area of the ice sheet, and large in several areas of mountain and coastal regions, where interpolation and extrapolation of field data are particularly unreliable. Remotely sensed data generally produce ratio values which are isotopically cooler.
\end{abstract}

\section{INTRODUCTION}

7Time series of surface air temperature for particular sites are among the most important data bases used to assess global change (e.g. Jones, 1994; Parker and others, 1995). Oxygen-isotope ratio values obtained from polar firn and ice samples are determined by complex phenomena that include the condensation history of air masses, but in practice are taken to indicate the temperature of condensation in the lower troposphere at the time of precipitation, and are used as proxy data for surface temperature (e.g. Dansgaard and others, 1973; Lorius and Merlivat, 1977). Applying diverse dating criteria, time series of oxygen-isotope ratio values obtained from deep ice cores yield complete temperature records of varying time resolutions covering millennia (e.g. Hecht, 1989; Jouzel and others, 1993). Values of $\delta^{18} \mathrm{O}$ (in this study, multi-year mean value of ${ }^{18} \mathrm{O} /{ }^{16} \mathrm{O}$ relative to Standard Mean Ocean Water, in \%o) (SMOW; repositories at the U.S. National Bureau of Standards, Washington, DC, and at the International Atomic Energy Agency, Vienna) need to be adjusted for ice flow, normally using modeling procedures that incorporate an assumed surface distribution of either $\delta^{18} \mathrm{O}$ or multi-year mean temperature values upstream of the sampling site (e.g. Robin, 1976; Budd and Young, 1983). The present study provides a benchmark distribution for any such modeling in studies of deep ice cores from Antarctica.
In the following sections we discuss aspects of:

(a) the sample-site dataset and $100 \mathrm{~km}$ grid data subsets.

(b) the general model derived using the whole sample-site dataset, and the possibly maximum regional differences at drainage-system scale within the general model.

(c) entity-specific models that result from splitting the sample-site data to represent locations exclusively on the conterminous grounded-ice area, and on ice-shelf areas (including islands and ice rises).

(d) two areal distributions of $\delta^{18} \mathrm{O}$ that result from the inversion of entity-specific models applied to $100 \mathrm{~km}$ grid data subsets, one based largely on data obtained from surface observations, and the other based largely on remotely sensed data.

(e) a comparison between the areal distribution of $\delta^{18} \mathrm{O}$ produced using the field and remotely sensed data subsets showing the distribution of residuals.

The principal differences between the present study and a preceding study (Giovinetto and Zwally, 1997) are the compilation of a significantly larger and overall more representative sampling-site dataset, an assessment of regional departures from the general model, the introduction of a remotely sensed grid data subset and the production of a contoured distribution based on it, as well as a discussion of 
residuals produced by the $\delta^{18} \mathrm{O}$ distributions based on the field and remotely sensed data subsets.

\section{SAMPLE-SITE DATABASE}

Our compilation of $\delta^{18} \mathrm{O}$ data for Antarctica aims to include all sampling sites reported in the literature, mainly building on two preceding compilations (Morgan, 1982; Giovinetto and Zwally, 1997) (Fig. 1). The number of sampling sites listed for the present study (562) is $38 \%$ greater than the number used in a preceding analysis (406; Giovinetto and Zwally, 1997). The increase is due in part to the inclusion of data for 33 sites in the Graham Land-Larsen Ice Shelfeastern Palmer Land region that were compiled but purposely excluded from analysis in the preceding study, and in part to the addition of data for 86 sites in the sector between $50^{\circ}$ and $110^{\circ} \mathrm{E}$ (Goodwin, 1990; Higham and Craven, 1997; Morgan and others, 1997). Due to an oversight, three sites on the eastern Filchner-Ronne Ice Shelf (Jenkins and Doake, 1991) are not included in the analyses.

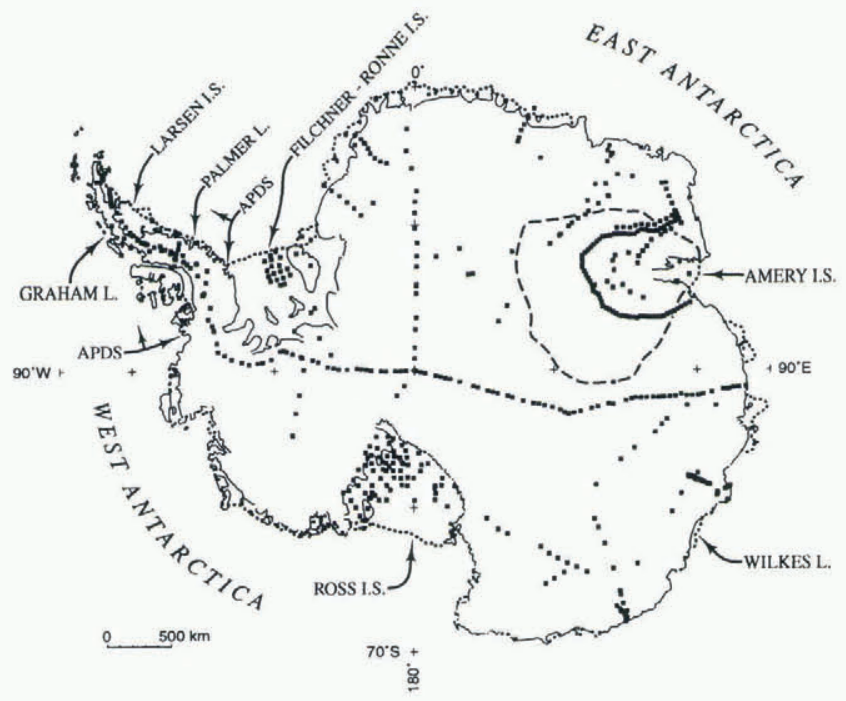

Fig. 1. Antarctica, showing the location of data sites and places mentioned in the text. The coastal extent of the drainage systems in the Antarctic Peninsula region is indicated by arrows labeled APDS, and the divide for the Lambert Glacier-Amery Ice Shelf drainage system is shown with dashes.

In the present study, $\delta^{18} \mathrm{O}$ data for four sites in the Lambert Glacier-Amery Ice Shelf drainage system were obtained by conversion of $\delta \mathrm{D}\left({ }^{2} \mathrm{H} /{ }^{1} \mathrm{H}\right.$ relative to SMOW, in $\%$ o) derived from a correlation between the two ratios for 27 sites in the same system:

$$
\begin{aligned}
\delta^{18} \mathrm{O} & =-6.296+(0.104 \delta D) ; \\
R & =0.899, \quad R^{2}=0.808, \quad \mathrm{rms}=1.345
\end{aligned}
$$

where $R$ is the coefficient of correlation, $R^{2}$ is the coefficient of determination, and $\mathrm{rms}$ is the root-mean-square residual.

The increase in the number of sampling sites gives this study two advantages over the preceding one (Giovinetto and Zwally, 1997). First, it improves the significance level of various statistics that result from any particular analysis; the number of sites that lie on the conterminous grounded ice increases by $44 \%$, from 296 to 427 , and on the area of ice shelves including islands and ice rises, by $23 \%$, from 110 to 135 . Secondly, the analyses include data for the sites in the Graham Land-Larsen Ice Shelf-eastern Palmer Land region (a sector spanning $15^{\circ}$ of longitude). Although not sampled by the grid, as discussed in the following section, the inclusion of data representative of coastal or maritime regions, i.e. of relatively high isotopic and surface temperatures, and of relatively short distances to open ocean, enhances model sensitivity for the remaining coastal regions sampled by the grid and spanning $345^{\circ}$ of longitude. This is an important development since even a cursory view of Figure 1 shows the bulk of data sites are largely representative of conditions in the interior.

\begin{tabular}{|c|c|c|c|c|c|c|}
\hline & \multirow[t]{3}{*}{ Set/subset } & \multirow{2}{*}{$\begin{array}{c}\text { Statistic } \\
\delta^{18} \mathrm{O}\end{array}$} & \multicolumn{4}{|c|}{ Variables } \\
\hline & & & $L$ & $H$ & $T$ & $D$ \\
\hline & & $\%$ & ${ }^{\circ} \mathrm{S}$ & $\mathrm{m}$ & $\mathrm{K}$ & $\mathrm{km}$ \\
\hline \multirow[t]{4}{*}{ N562 } & Mean & -33.80 & 74.74 & 1596 & 241.4 & 1178 \\
\hline & Std dev. & 10.28 & 6.09 & 1129 & 11.8 & 447 \\
\hline & Min. & -58.40 & 62.02 & 1 & 215.5 & 282 \\
\hline & Max. & -9.33 & 90.00 & 3740 & 269.4 & 2250 \\
\hline \multirow[t]{4}{*}{$N 80$} & Mean & -40.93 & 73.55 & 2523 & 233.4 & 1301 \\
\hline & Std dev. & 5.05 & 2.06 & 466 & 6.0 & 213 \\
\hline & Min. & -54.40 & 69.47 & 64 & 217.7 & 799 \\
\hline & Max. & -19.00 & 77.00 & 3408 & 253.1 & 1688 \\
\hline \multirow[t]{4}{*}{$N 76$} & Mean & -22.99 & 70.42 & 1004 & 255.6 & 746 \\
\hline & Std dev. & 5.89 & 4.26 & 731 & 6.2 & 304 \\
\hline & Min. & -37.50 & 62.02 & 1 & 241.1 & 282 \\
\hline & Max. & -9.33 & 79.75 & 2131 & 269.4 & 1484 \\
\hline \multirow[t]{4}{*}{$N 427$} & Mean & -36.20 & 73.70 & 2071 & 238.8 & 1165 \\
\hline & Std dev. & 10.44 & 5.93 & 856 & 12.0 & 476 \\
\hline & Min. & -58.40 & 62.02 & 40 & 215.5 & 282 \\
\hline & Max. & -9.33 & 90.00 & 3740 & 269.1 & 2250 \\
\hline \multirow[t]{4}{*}{$N 135$} & Mean & -26.20 & 78.01 & 95 & 250.0 & 1217 \\
\hline & Std dev. & 4.36 & 5.41 & 159 & 5.7 & 337 \\
\hline & Min. & -34.80 & 62.25 & 1 & 241.5 & 282 \\
\hline & Max. & -9.05 & 84.60 & 1650 & 269.4 & 1650 \\
\hline
\end{tabular}

Table 1. Descriptive statistics for each dataset and subset

The sample-site data consist of $\delta^{18} \mathrm{O}$ as the dependent variable (Table 1: $N 562$, where $N$ is the number of samples in the dataset or subset) and four so-called independent variables. Of these, the first three are obtained from the $\delta^{18} \mathrm{O}$ sources themselves: latitude $\left(L\right.$, in $\left.{ }^{\circ} \mathrm{S}\right)$, surface elevation $(H$, in $\mathrm{m}$ above mean sea level, obtained for most sites from either surface traverse or flight altimetry) and mean annual surface temperature $(T$, in $\mathbf{K}$, obtained for most sites from firn temperature measurements at a depth of $10 \mathrm{~m}$ ). We add a fourth: mean annual shortest distance to open ocean, denoted by the $20 \%$ sea-ice concentration boundary in 1973-82 $(D$, in $\mathrm{km})$. We obtain the data using 15 day mean distributions of the boundary centered on 15 February and 15 September, as compiled by the United States Navy (1985) following a procedure described elsewhere (Giovinetto and Zwally, 1996).

\section{GRIDPOINT DATABASE}

Inversions of the models derived from stepwise analyses (presented in the following sections) are applied to a $100 \mathrm{~km}$ grid database in which each gridpoint location is defined by latitude and longitude, and assigned values of mean annual surface temperature, mean annual shortest distance to open ocean, 


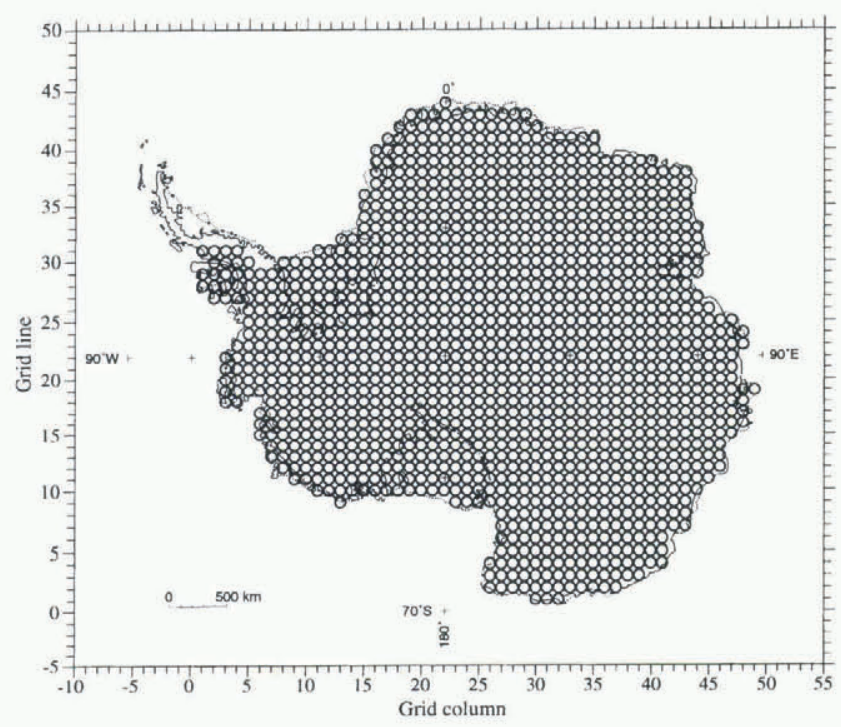

Fig. 2. Distribution of gridpoint locations (N1351). Grid-lines and grid columns are $100 \mathrm{~km}$ apart. Grid sampling excludes the Graham Land-Larsen Ice Shelf-eastern Palmer Land region.

and surface elevation obtained in two subsets. Information on the grid and the grid data subsets follows.

The grid sampling provides 1351 gridpoint locations determined overlaying a pattern of gridlines $100 \mathrm{~km}$ apart and parallel to meridians $90^{\circ} \mathrm{W}$ and $90^{\circ} \mathrm{E}$, and grid columns $100 \mathrm{~km}$ apart and parallel to meridians $0^{\circ}$ and $180^{\circ}$, on a polar stereographic projection with standard line at $71^{\circ} \mathrm{S}$ (Fig. 2). Grid sampling excludes the Graham LandLarsen Ice Shelf-eastern Palmer Land region for three reasons. Firstly, ice caps and glaciers in the region are not part of the ice sheet proper. Secondly, field data obtained in the region cannot be interpolated reliably due to its mountainous topography. Thirdly, grid data would not produce reliable contouring since there are relatively few gridpoints on each gridline overlying the region.

Differences between the field and remotely sensed data subsets involve qualitative and quantitative differences, as well as differences in areal and temporal distributions. Briefly, these differences may be classified as "general" and "specific":

\section{(1) General differences}

(i) Qualitative differences are defined by the contrast between the field subset, compiled from observations made by hundreds of observers using many techniques and methodologies through periods of diverse duration distributed over several decades, and the remotely sensed subset, collected using relatively few sensors and algorithms and practically without interruption for specific periods ranging from l year to approximately two decades.

(ii) Differences in areal distribution are defined by the contrast between the field subset, compiled from observations in areas limited by logistics (i.e. near widespread semi-permanent stations or along traverse routes), and the remotely sensed subset, compiled from normally full-area coverage data generally available as mean values for grid squares with side lengths that range from a few $\mathrm{km}$ to $30 \mathrm{~km}$.

\section{(2) Specific differences}

(i) Surface elevation. The elevation values entered in the field subset $\left(H_{\mathrm{s}}\right.$, in $\left.\mathrm{m}\right)$ were visually interpolated from $100 \mathrm{~m}$ contour lines as drawn from extensive compilations of surface altimetry data obtained by traverse altimetry leap-frog methods, aircraft surface-altimetry data, etc. (Drewry, 1983). The elevation values entered in the remotely sensed subset $\left(H_{\mathrm{r}}\right.$, in $\left.\mathrm{m}\right)$ were obtained for locations northward of approximately $81.5^{\circ} \mathrm{S}$ by bilinear interpolation from ERS-1 radar altimeter data provided by A. Brenner and J. DiMarzio (personal communication, 1997).

(ii) Mean annual surface temperature. The temperature values entered in the field subset $\left(T_{\mathrm{s}}\right.$, in $\left.\mathrm{K}\right)$ were visually interpolated from an isotherm pattern manually drawn in increments of $5 \mathrm{~K}$ using data for approximately 700 locations (manned and automatic weather stations, traverse firn temperature measurements at diverse depths) representative of mean values for periods of 1-30 years ending on any year between 1948 and 1988 (Giovinetto and others, 1990). The elevation values entered in the remotely sensed subset $\left(T_{\mathrm{r}}\right.$, in $\left.\mathrm{K}\right)$ were obtained by bilinear interpolation of Nimbus 7 temperature humidity infrared radiometer for 1979 (Comiso, 1994).

(iii) Mean annual shortest distance to open ocean. The two sea-ice-extent distributions used to compile the field and remotely sensed data subsets may be considered to be remotely sensed data. However, the procedures to obtain the distance values for each subset are drastically different. The distribution used to determine distances for the field subset $\left(D_{\mathrm{s}}\right.$, in $\left.\mathrm{km}\right)$ is the same as that described above for the data base corresponding to $\delta^{18} \mathrm{O}$ sampling sites. We estimated the distance by summation of factored distances measured to the $20 \%$ sea-ice concentration boundary for only two semi-monthly means (one each to the winter maximum and summer minimum sea-ice extents as compiled for 1973-82 by the United States Navy (1985) (Giovinetto and Zwally, 1996)). The other sea-ice-extent distribution used to determine distances for the remotely sensed subset $\left(D_{\mathrm{r}}\right.$, in $\left.\mathrm{km}\right)$ involved a single measurement to an integrated $20 \%$ sea-ice concentration boundary for 1978-95 as compiled from Nimbus-7 scanning multichannel microwave radiometer data, and three Defense Meteorological Satellite Program special sensor microwave imager data from Cavalieri and others (1997).

Differences between other field and remotely sensed data subsets produced notably different areal distributions of $\delta^{18} \mathrm{O}$ for the Greenland ice sheet (Zwally and Giovinetto, 1997b), as well as different estimates of net mass accumulation at the surface or surface balance for the Antarctic and Greenland ice sheets (Zwally and Giovinetto, 1997a).

\section{GENERAL MODEL}

A common multivariate regression model obtained using N562,

$$
\begin{aligned}
\delta^{18} \mathrm{O}= & -134.242+(-0.086 L)+\left(-2.704^{-3} H\right) \\
& +\left(0.484^{-3} T\right)+\left(-4.752^{-3} D\right) ; \\
R= & 0.972, \quad R^{2}=0.945, \quad \text { rms }=2.41,
\end{aligned}
$$

would be implicitly biased by moderate to strong correlation between $\quad T, H(R=-0.829), D, L(R=0.894)$, and $T, D(R=-0.922)$ (Table 2). The covariation problem is 
Table 2. Correlation matrixes for each dataset and subset

\begin{tabular}{|c|c|c|c|c|c|c|}
\hline & \multirow[t]{2}{*}{ Set/subset } & \multirow[b]{2}{*}{$\delta^{18} \mathrm{O}$} & \multicolumn{4}{|c|}{ Variables } \\
\hline & & & $L$ & $H$ & $T$ & $D$ \\
\hline N562 & $\begin{array}{l}\delta^{18} \mathrm{O} \\
\mathrm{L} \\
\mathrm{H} \\
\mathrm{T} \\
\mathrm{D}\end{array}$ & $\begin{array}{r}1.000 \\
-0.459 \\
-0.821 \\
0.958 \\
-0.704\end{array}$ & $\begin{array}{r}1.000 \\
-0.015 \\
-0.409 \\
0.894\end{array}$ & $\begin{array}{r}1.000 \\
-0.829 \\
0.307\end{array}$ & $\begin{array}{l}1.000 \\
0.922\end{array}$ & 1.000 \\
\hline$N 80$ & $\begin{array}{l}\delta^{18} \mathrm{O} \\
\mathrm{L} \\
\mathrm{H} \\
\mathrm{T} \\
\mathrm{D}\end{array}$ & $\begin{array}{r}1.000 \\
-0.545 \\
-0.875 \\
0.846 \\
-0.619\end{array}$ & $\begin{array}{r}1.000 \\
0.320 \\
-0.418 \\
0.978\end{array}$ & $\begin{array}{r}1.000 \\
-0.881 \\
0.432\end{array}$ & $\begin{array}{r}1.000 \\
-0.551\end{array}$ & 1.000 \\
\hline$N 76$ & $\begin{array}{l}\delta^{18} \mathrm{O} \\
\mathrm{L} \\
\mathrm{H} \\
\mathrm{T} \\
\mathrm{D}\end{array}$ & $\begin{array}{r}1.000 \\
-0.732 \\
-0.509 \\
0.910 \\
-0.731\end{array}$ & $\begin{array}{r}1.000 \\
0.354 \\
-0.824 \\
0.978\end{array}$ & $\begin{array}{r}1.000 \\
-0.612 \\
0.391\end{array}$ & $\begin{array}{r}1.000 \\
-0.833\end{array}$ & 1.000 \\
\hline$N 427$ & $\begin{array}{l}\delta^{18} \mathrm{O} \\
\mathrm{L} \\
\mathrm{H} \\
\mathrm{T} \\
\mathrm{D}\end{array}$ & $\begin{array}{r}1.000 \\
-0.683 \\
-0.868 \\
0.957 \\
-0.809\end{array}$ & $\begin{array}{r}1.000 \\
0.376 \\
-0.591 \\
0.930\end{array}$ & $\begin{array}{r}1.000 \\
-0.897 \\
0.557\end{array}$ & $\begin{array}{r}1.000 \\
-0.728\end{array}$ & 1.000 \\
\hline$N 135$ & $\begin{array}{l}\delta^{18} \mathrm{O} \\
\mathrm{L} \\
\mathrm{H} \\
\mathrm{T} \\
\mathrm{D}\end{array}$ & $\begin{array}{r}1.000 \\
-0.801 \\
-0.170 \\
0.833 \\
-0.784\end{array}$ & $\begin{array}{r}1.000 \\
0.031 \\
-0.871 \\
0.917\end{array}$ & $\begin{array}{r}1.000 \\
-0.188 \\
0.109\end{array}$ & $\begin{array}{r}1.000 \\
-0.839\end{array}$ & 1.000 \\
\hline
\end{tabular}

minimized by applying stepwise procedures in either the forward or backward mode (Cochran, 1957; Davis and Sampson, 1973; Williams, 1986; Tabachnick and Fidell, 1989) (Table 3).

Stepwise procedures are subject to constraints defined by a minimum confidence level desired in the regression model. The constraint is determined by the $F$ value ( $F$ statistic under the null hypothesis showing a probability $P$ equal to or less than the selected confidence limit) which is in turn determined from standard mathematical tables on the basis of the number of data entries and the number of so-called independent variables.

In this and the following sections, we performed stepwise regression methods, confirming results obtained in the forward mode by repeating all analyses in the backward mode. All statistics are significant at the $99 \%$ confidence level $(P \leq 0.01)$ unless noted otherwise. Variables in any equation based on stepwise regression models are listed in the order in which they entered the particular model.

In the forward mode, at step zero, all independent variables are ranked by the $R$ value obtained running simple regression analysis between the dependent and each one of the independent variables. The variable that produces the largest $R$ value enters the model at step one, and the unexplained variance (residual $\delta^{18} \mathrm{O}$ values) becomes the dependent variable in a reiteration of the procedure with the remaining independent variables. The largest $R$ value obtained determines which variable enters the model at step two, and so on. Reiteration of the procedure ceases when there are no independent variables remaining, or if one or more of the remaining variables does not significantly improve the overall explanation of variance. In some cases, all variables enter the model, but the intercept value and

Table 3. Summary of stepwise analyses $\delta^{18} O$ as the dependent variable)

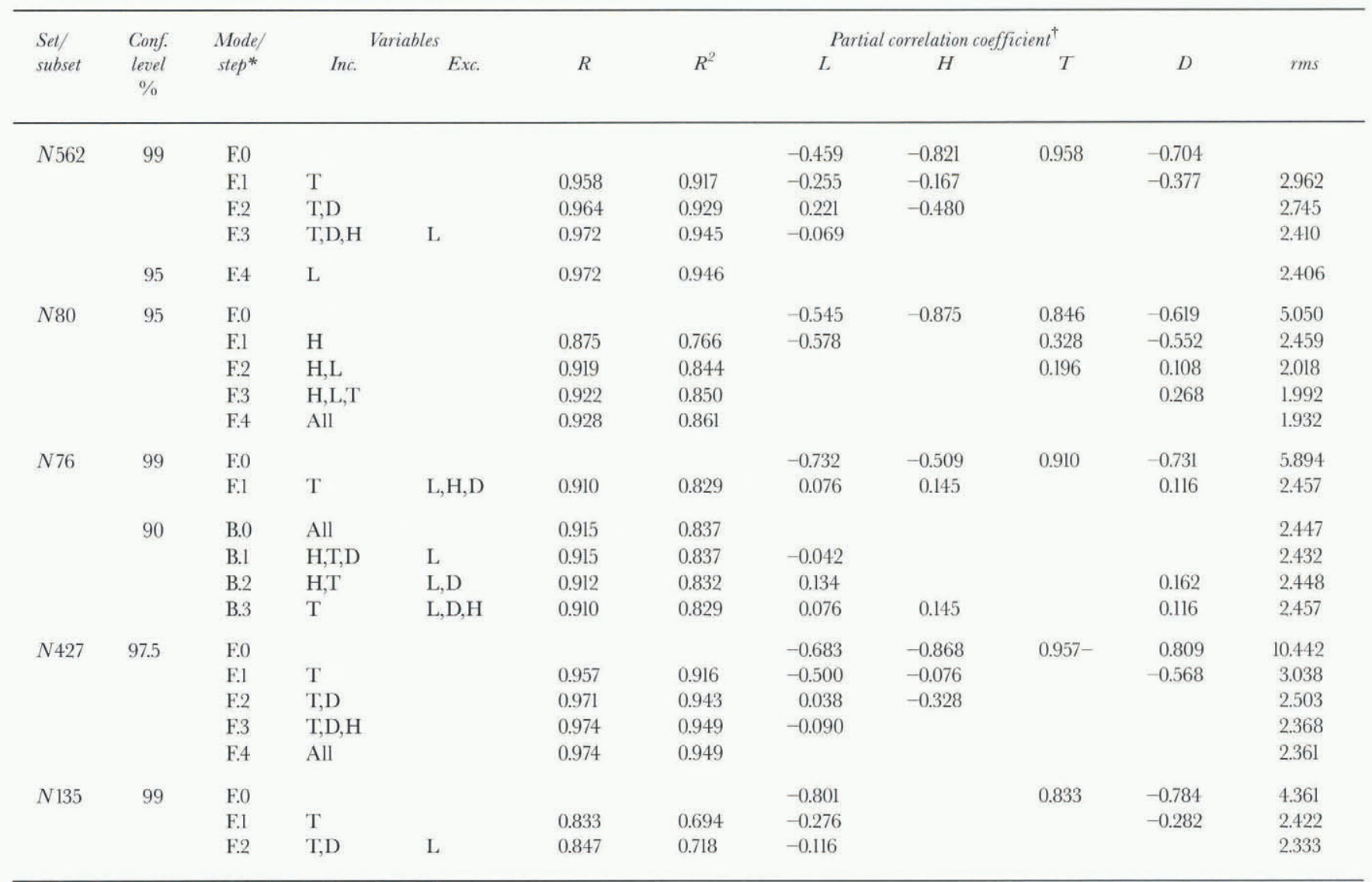

\footnotetext{
* Stepwise analysis mode (F, forward; B, backward) and step number, starting with step zero.

$\dagger$ At step zero, bivariate correlation coefficients as in Table 2; partial correlation coefficients at subsequent steps.
} 
regression coefficient values for each variable are different from that obtained from common multivariate regression analysis, as will be shown below. It should be noted that the values of the intercept and of the coefficient of each variable that enter the model change at each step. Moreover, if the purpose of a particular analysis is to describe a physical rather than a statistical model, one or more of the variables can be forced into the model at any step; however, we do not do this in the present study.

In the backward mode, at step zero, all independent variables are in the model. If a variable does not contribute significantly to the explanation of variance, it will be removed at step one, and so on at each following step. If all variables contribute at the selected significance level, no variable will be removed. The use of the backward mode is recommended when there is no interest in knowing the order in which the variables enter a model. Its use may also be recommended to confirm or question the marginal inclusion or exclusion of a variable in the forward procedure. Examples of this use of the backward mode applied to similar sets of variables can be found in studies of the areal distribution of $\delta^{18} \mathrm{O}$ in Greenland ( $Z$ wally and Giovinetto, 1997b) and in northeastern Canada (Giovinetto and others, 1997). Our analyses are performed using available software (e.g. StatView ${ }^{\mathbb{R}}$ (Haycock and others, 1992)).

In the first stepwise analysis of $N 562$, only three variables entered the model $(T, D, H)$ :

$$
\begin{aligned}
\delta^{18} \mathrm{O}= & -142.006+(0.493 T)+\left(-5.802^{-3} D\right) \\
& +\left(-2.488^{-3} H\right) ; \\
R= & 0.972, \quad R^{2}=0.945, \quad \text { rms }=2.41 .
\end{aligned}
$$

However, a confidence level of $99 \%$ is unnecessarily high in the case of relatively small datasets widespread over a large area (i.e. $N<10^{4}$, over an area of the order of $10^{7} \mathrm{~km}^{2}$ ) and in which the values of $\delta^{18} \mathrm{O}, T$ and $D$ are obtained as a mean for different periods that in many cases do not overlap, as described in a preceding section.

The $F$-to-enter value for $L$ at the end of step three in the procedure (2.682) is smaller than that set for the model at the $99 \%$ confidence level $(3.800)$. We run a second stepwise analysis at the $95 \%$ confidence level $(F$-to-enter $=2.620)$ and $L$ enters the model:

$$
\begin{aligned}
\delta^{18} \mathrm{O}= & -128.905+(0.487 T)+\left(-2.230^{-3} D\right) \\
& +\left(-3.091^{-3} H\right)+(-0.194 L) ; \\
R= & 0.972, \quad R^{2}=0.946, \quad \text { rms }=2.41 .
\end{aligned}
$$

In an inversion, Equation (4) would be more sensitive to $L$ than Equation (3), where the contribution of $L$ is only through covariation with $D$ and $T$. The use of Equation (4) would be preferable for Antarctica because, lower confidence level withstanding, the ice sheet extends over $20^{\circ}$ of latitude.

We assess the probable regional variations within the general model comparing two models from physiographically distinct regions. For this purpose we select an "interior" or "continental" region (the Lambert Glacier-Amery Ice Shelf drainage system, henceforth referred to as the Lambert-Amery region) and a "coastal" or "maritime" region (the drainage systems in the Antarctic Peninsula region, which includes Graham and Palmer Lands as well as the islands and ice shelves: clockwise from approximately $76.5^{\circ} \mathrm{W}$, the George VI, Wilkins, Wordie and Larsen Ice Shelves, henceforth referred to as the Peninsula region) (Fig. 1; Table 1).

In the Lambert-Amery region the data $(N 80)$ are char-

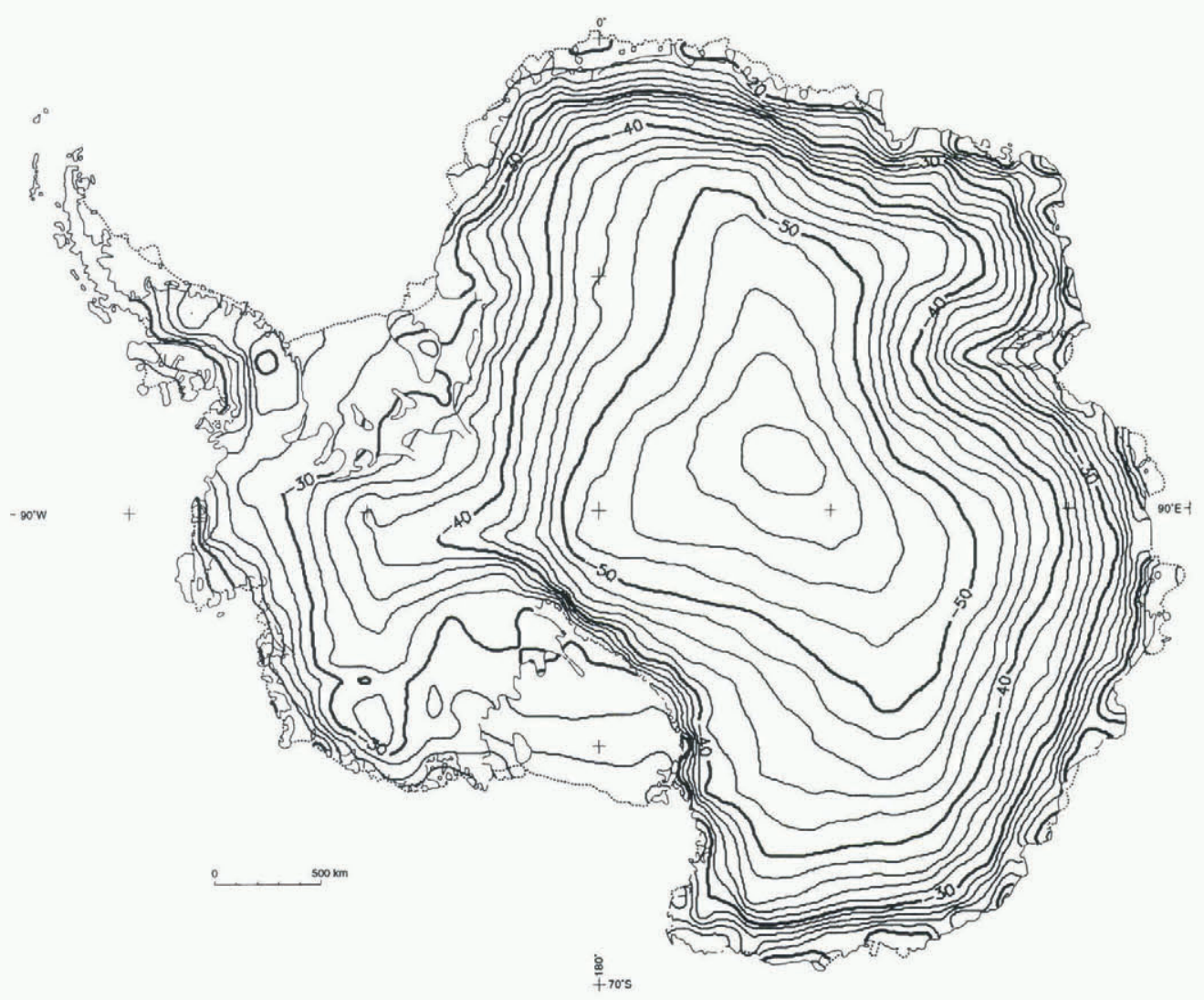

Fig. 3. Distribution of $\delta^{18} O_{\mathrm{s}}$ produced by inversions of entity-specific models applied to field grid-data subsets (N1182 for the conterminous grounded ice, and N169 for the ice-shelf areas). 


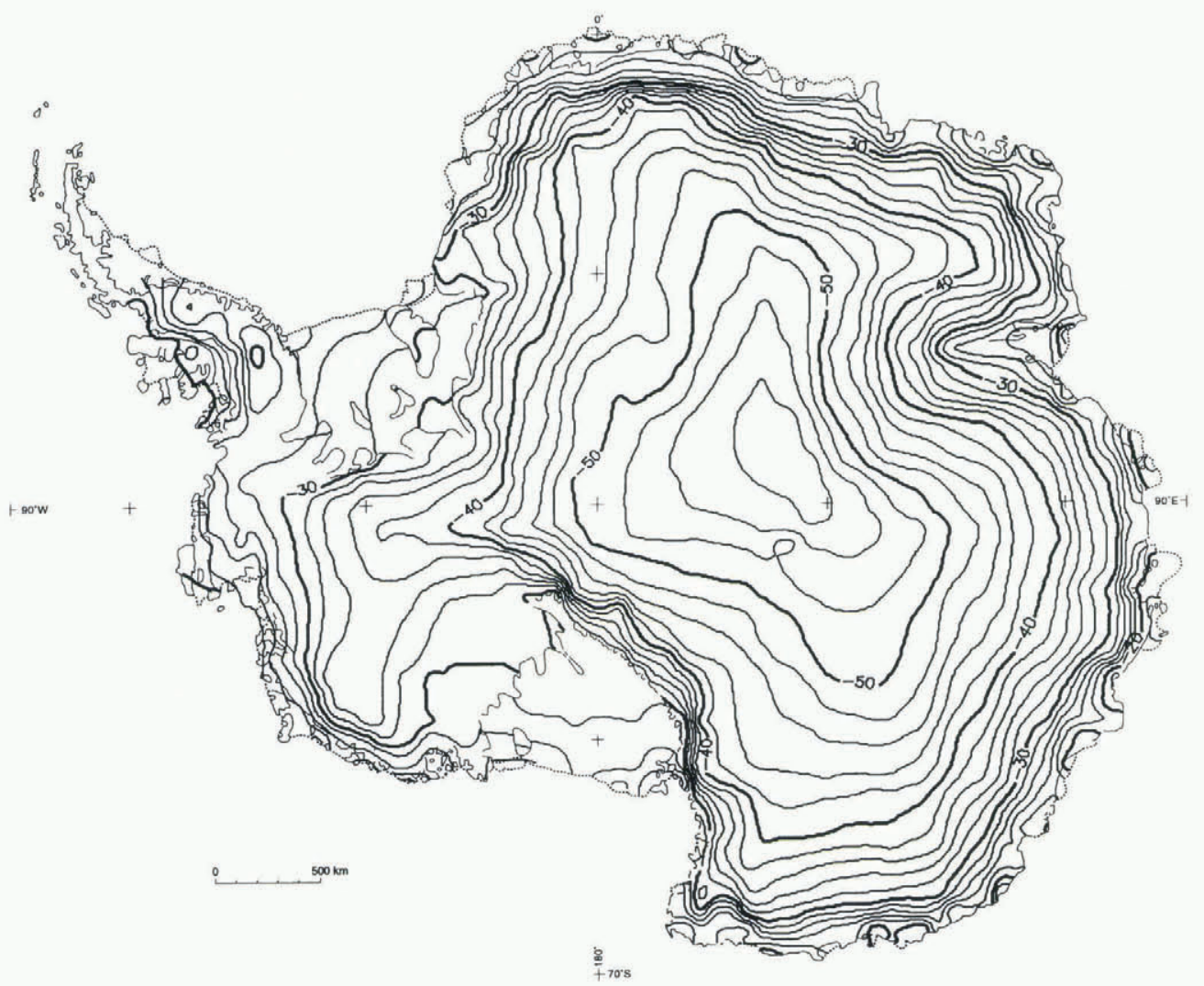

Fig. 4. Distribution of $\delta^{18} \mathrm{O}_{\mathrm{r}}$ produced by inversions of entity-specific models applied to remotely sensed grid-data subsets (N1182 for the conterminous grounded ice, and N169 for the ice-shelf areas).

acterized by relatively high latitude, high surface elevation, low surface temperature and long distance to open ocean. Precipitation in this area has a large component due to advective uplift, and extensive surface slopes swept by strong katabatic flow redistribute fallen snow over long distances (Goodwin and others, 1994).

In the Peninsula region the data $(\mathcal{N} 76)$ are characterized by relatively low latitude, low to intermediate surface elevation, high surface temperature, and short distance to open ocean. Precipitation in this region is largely due to cyclonic activity (Turner and others, 1995) as well as advective uplift, and surface slopes are relatively short although steep; thus fallen snow transport over long distances is not important, although large changes in elevation between the location where a precipitation event occurs and the actual accumulation site introduces uncertainty in the analysis.

In the case of the Lambert-Amery, only $H$ and $L$ enter the model at the $99 \%$ confidence level $\left(R=0.919, R^{2}=0.844\right.$, $\mathrm{rms}=2.018$, and the $F$ value-to-enter must be reduced to the $95 \%$ level for all four independent variables to enter:

$$
\begin{aligned}
\delta^{18} \mathrm{O}= & 58.092+\left(-6.583^{-3} H\right)+(-2.313 L) \\
& +(0.277 T)+(0.018 D) ; \\
R= & 0.928, \quad R^{2}=0.861, \quad \text { rms }=1.93 .
\end{aligned}
$$

In the case of the Peninsula, only $T$ enters the model, and $D, L$ and $H$ do not enter even at the $90 \%$ confidence level (a backward run in the stepwise procedure removes $H$ first, followed by $L$ and $D$, in this order):

$$
\begin{aligned}
\delta^{18} \mathrm{O} & =-244.230+(0.865 T) ; \\
R & =0.910, \quad R^{2}=0.829, \quad \text { rms }=2.46 .
\end{aligned}
$$

The discrepancy between the models described in Equations (5) and (6) is large, albeit a probable maximum difference between particular models corresponding to regions of org/10.3189/50260305500018097 Published online by Cambridge University Press drainage-system scale. Nevertheless, the difference indicates the need to establish subregional models for drainage-basin areas, and shows that flowline studies such as may be needed for detailed intrepretation of $\delta^{18} \mathrm{O}$ series obtained in deep cores must be narrowly defined.

\section{ENTITY-SPECIFIC MODELS}

We determine the entity-specific models for the conterminous grounded ice $(N 427)$ and the ice-shelf areas which include ice rises and islands attached by ice (N135). The $N 427$ model,

$$
\begin{aligned}
\delta^{18} \mathrm{O}= & -146.270+(0.511 T)+\left(-6.114^{-3} D\right) \\
& +\left(-2.281^{-3} H\right) ; \\
R= & 0.974, \quad R^{2}=0.949, \quad \text { rms }=2.37,
\end{aligned}
$$

is robust. Although $L$ does not enter at the $99 \%$ confidence level, it does at the $97.5 \%$ level in the form

$$
\begin{aligned}
\delta^{18} \mathrm{O}= & -137.554+(0.504 T)+\left(-4.723^{-3} D\right) \\
& +\left(-2.509^{-3} H\right)+(-0.111 L) ; \\
R= & 0.974, \quad R^{2}=0.949, \quad \text { rms }=2.36,
\end{aligned}
$$

which we select for application to the grid data for the grounded ice area (N1128). The N135 model,

$$
\begin{aligned}
\delta^{18} \mathrm{O} & =-135.316+(0.455 T)+\left(-3.704^{-3} D\right) ; \\
R & =0.847, \quad R^{2}=0.718, \quad \text { rms }=2.33,
\end{aligned}
$$

is also robust and adequate for application to the grid data for the ice-shelf areas (N169). Elevation is excluded from the analyses for ice-shelf areas, and $L$ does not enter the model even if the $F$-to-enter value is reduced well below the $90 \%$ confidence level.

Inversions of the entity-specific models applied to the 


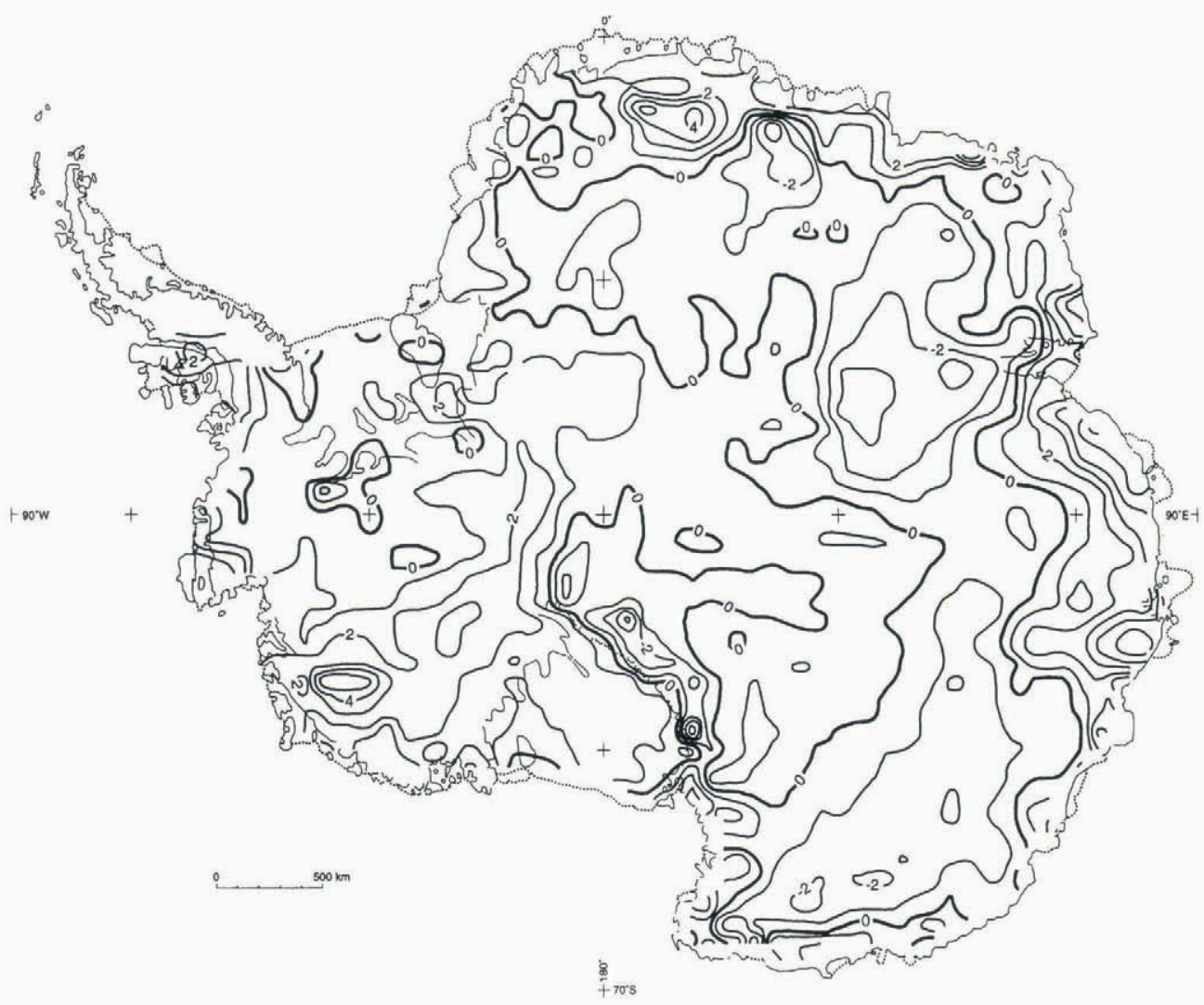

Fig. 5. Distribution of $\Delta^{18} \mathrm{O}$; residuals are the difference between $\delta^{18} \mathrm{O}_{\mathrm{s}}$ and $\delta^{18} \mathrm{O}_{\mathrm{r}}$.

grid-data subsets produce combined contoured distributions of $\delta^{18} \mathrm{O}_{\mathrm{s}}$ (Fig. 3; inversion of Equation (8) applied to N1128 $\left(T_{\mathrm{s}}, D_{\mathrm{s}}, H_{\mathrm{s}}, L\right)$ and of Equation (9) applied to N169 $\left(T_{\mathrm{s}}, D_{\mathrm{s}}\right)$ ), and of $\delta^{18} \mathrm{O}_{\mathrm{r}}$ (Fig. 4; inversions of Equations (8) and (9) applied as stated above and substituting $\left(T_{\mathrm{r}}, D_{\mathrm{r}}, H_{\mathrm{r}}, L\right)$ and $\left(T_{\mathrm{r}}, D_{\mathrm{r}}\right)$, respectively). Isopleths shown on ice shelves other than the Filchner-Ronne, Amery and Ross should be viewed with caution because the smaller ice shelves are sampled by insufficient gridpoints to produce reliable contours. We use a contouring algorithm based on a closest-neighbor approach involving the eight nearest gridpoints (SURFACE III; Sampson, 1988). In our grid, each point value may be deemed to represent the value at the center of a square with side lengths of $100 \mathrm{~km}$, while the surface created in contouring to obtain the interpolated value for the ninth point at the center of the pattern is determined from data distributed in a square with side lengths of $300 \mathrm{~km}$.

\section{DISGUSSION AND GONGLUSIONS}

A visual comparison of the distributions obtained from the field and remotely sensed data shows that both subsets produce the same general pattern, with minor differences. For example, the distribution of $\delta^{18} \mathrm{O}_{\mathrm{s}}$ is characterized by relatively smooth isopleths. This is to be expected because prior to the compilation of the field grid-data subset, both isotherms and contour lines are normally drawn to smooth the scatter of in situ temperature and elevation data, and are interpolated and extrapolated over long distances (e.g. between and beyond over-snow traverse routes). In contrast, the distribution of $\delta^{18} \mathrm{O}_{\mathrm{r}}$ is not affected by smoothing prior to the compilation of the remotely sensed gridpoint data subset as it pertains to interpolation and extrapolation over long distances, and therefore the distribution pattern shows more detail.

The distribution of residuals $\left(\Delta^{18} \mathrm{O}=\delta^{18} \mathrm{O}_{\mathrm{s}}-\delta^{18} \mathrm{O}_{\mathrm{r}}\right)$ shown in Figure 5 indicates that $\pm \Delta^{18} \mathrm{O}$ values are relatively small in most of the area of the ice sheet, where they are equal to or less than the summation of rms values (srms $\leq \pm 3.3$ ) of any two models used in the inversions. This is to say, on the conterminous grounded-ice area, where Equation (8) is applied, srms $=\sqrt{2}\left(2.36^{2}\right)$, and on the ice-shelf areas, where Equation (9) is applied, srms $=\sqrt{2}\left(2.33^{-2}\right)$. In general, the $\Delta^{18} \mathrm{O}$ values are larger than srms in mountain regions and/or coastal zones:

In West Antarctica, including the Ross and FilchnerRonne Ice Shelves, an area centered on the mountainous region of the Executive Committee Range $\left(77^{\circ} \mathrm{S}, 123^{\circ} \mathrm{W} ; \Delta^{18} \mathrm{O}=5\right)$.

In East Antarctica, an area along the segment of the Transantarctic Mountains lying west of the Ross Ice Shelf $\left(\Delta^{18} \mathrm{O}=-4\right)$, and others along the coastal zone where $\Delta^{18} \mathrm{O} \geqslant 4$, centered at longitudes of approximately $10^{\circ}, 45^{\circ}, 65^{\circ}, 80^{\circ}$ and $104^{\circ} \mathrm{E}$.

All of the areas listed above correspond to mountain regions and/or regions of intense katabatic air flow (e.g. Parish and Bromwich, 1987). The sign of the residuals shows that for those areas and where $\Delta^{18} \mathrm{O} \geqslant$ smrs (the Transantarctic Mountains area west of the Ross Ice Shelf excepted), the use of remotely sensed data produces ratio values which are isotopically cooler. This is to be expected since the type of topography and/or the implicit surface slope gradient in those areas, as well as the surface temperature variability induced by katabatic flow (e.g. Wendler and others, 1993), lead to unreliable long-distance interpolation and extrapolation of field data on temperature and eleva- 
tion. In those areas $\delta^{18} \mathrm{O}_{\mathrm{r}}$ values are generally more reliable than $\delta^{18} \mathrm{O}_{\mathrm{s}}$ values.

The characteristics of the models provide a perspective to assess two aspects described by the analyses. One is the impact of including data for 33 sites located in Graham Land, Larsen Ice Shelf and eastern Palmer Land, and which are not sampled by the grid pattern; their inclusion enhanced the representation of the models for the coastal zone of both East and West Antarctica, with no significant decay in diagnostic statistics (cf., respectively, $R$ and $\mathrm{rms}$ values for Equations (8) and (9) and (4) and (5) in a preceding study (Giovinetto and Zwally, 1997)).

The other aspect is the regional variation at drainagesystem scale that may be expected within the general model (Equations (3) and (4)) as illustrated by the models for the Lambert-Amery and Peninsula regions (Equation (5) and (6), respectively), which suggest a variety of so-called independent variable combinations suffice to attain robust models $\left(R^{2} \geq 0.8\right)$. Nevertheless, we close with a note of caution as greater model variations should be expected for particular drainage basins and flowlines.

\section{ACKNOWLEDGEMENTS}

The authors gratefully acknowledge the contributions of M. Delmotte (Laboratoire de Modélisation du Climat et de l'Environnement, Centre d'Études de Saclay) who completed the isotopic analyses for samples from the LambertAmery region, and of T. Medhurst, R. Thwaites, B. Hazelton, R. Kiernan and M. Higham (all from Australian National Antarctic Research Expeditions), who collected the firn samples for the same region, as well as other contributions by C. Conrad (Massachusetts Institute of Technology), S. Fiegles (Raytheon STX, (formerly Hughes STX)) and D. Phillips (University of Calgary).

\section{REFERENCES}

Budd, W. F. and N.W. Young. 1983. Application of modelling techniques to measured profiles of temperatures and isotopes. In Robin, G. de Q., ed. The climatic record in polar ice sheets. Cambridge, Cambridge University Press, 150-177.

Cavalieri, D. J., P. Gloersen, C. L. Parkinson, J. C. Comiso and H. J. Zwally. 1997. Observed hemispheric asymmetry in global sea ice changes. Science, 278(5340), 1104-1106.

Cochran, W. G. 1957. Analysis of covariance: its nature and uses. Biometrics, $13(3), 261-281$.

Comiso, J. C. 1994. Surface temperatures in the polar regions from Nimbus 7 temperature humidity infrared radiometer. 7. Geophys. Res., 99(C3), $5181-5200$

Dansgaard, W., S.J. Johnsen, H. B. Clausen and N. Gundestrup. 1973. Stable isotope glaciology. Medd. Gronl., $197(2)$.

Davis, J. C. and R. J. Sampson. 1973. Statistics and data analysis in geology. New York, etc., John Wiley and Sons.

Drewry, D. J. 1983. The surface of the Antarctic ice sheet. In Drewry, D. J., ed. Antarctica: glaciological and geophysical folio. Cambridge, University of Cambridge. Scott Polar Research Institute, Sheet 2.

Giovinetto, M. B. and H. J. Zwally. 1996. Annual changes in sea ice extent and of accumulation on ice sheets: implications for sea level variability.
Z. Gletscherkd. Glazialgeol., 31, Part 1, 1995, 39-49.

Giovinetto, M. B. and H.J. Zwally. 1997. Areal distribution of the oxygenisotope ratio in Antarctica: an assessment based on multivariate models. Ann. Glaciol., 25, 153-158.

Giovinetto, M. B., N. M. Waters and C. R. Bentley. 1990. Dependence of Antarctic surface mass balance on temperature, elevation, and distance to open ocean. 7. Geophys. Res., 95(D4), 3517-3531.

Giovinetto, M. B., G. Holdsworth, D. A. Fisher, N. M. Waters and H.J. Zwally. 1997. An assessment of the regional distribution of the oxygenisotope ratio in northeastern Canada. Ann. Glaciol., 25, $214-219$.

Goodwin, I. D. 1990. Snow accumulation and surface topography in the katabatic zone of eastern Wilkes Land, Antarctica. Antarct. Sci., 2(3), 235-242.

Goodwin, I. D., M. Higham, I. Allison and R. Jiawen. 1994. Accumulation variation in eastern Kemp Land, Antarctica. Ann. Glaciol., 20, 202-206.

Haycock, K.A. and 16 others. 1992. StatView ${ }^{\mathrm{R}}$. Berkeley, CA, Abacus Concepts Inc.

Hecht, A. D. 1989. Long-term ice core records and global environmental changes. In Oeschger, H. and C. C. Langway, Jr, eds. The environmental record in glaciers and ice sheets. Chichester, etc., John Wiley and Sons, 379-388.

Higham, M. and M. Craven. 1997. Surface mass balance and snow surface properties from the Lambert Glacier basin traverses 1990-94. Hobart, Tasmania, Cooperative Research Centre for the Antarctic and Southern Ocean Environment. (Research Report 9.)

Jenkins, A. and C. S. M. Doake. 1991. Ice ocean interaction on Ronne Ice Shelf, Antarctica. J. Geophys. Res., 96(C1), 791-813.

Jones, P. D. 1994. Hemispheric surface temperature variations: a reanalysis and an update to 1993. f. Climate, 7(11), 1794-1802.

Jouzel, J. and 16 others. 1993. Extending the Vostok ice-core record of palaeoclimate to the penultimate glacial period. Nature, 364(6436), 407-411.

Lorius, C. and L. Merlivat. 1977. Distribution of mean surface stable isotope values in East Antarctica. International Association of Hydrological Sciences Publication 118 (Symposium at Grenoble 1975 - Isotopes and Impurities in Snow and Ice ), 127-137.

Morgan, V. I. 1982. Antarctic ice sheet surface oxygen isotope values. 7 . Glaciol., 28 (99), 315-323.

Morgan, V. I., C.W. Wookey, Li Jun, T. D. van Ommen, W. Skinner and M. F. Fitzpatrick. 1997. Site information and initial results from deep drilling on Law Dome, Antarctica. J. Glaciol., 43(143), 3-10.

Parish, T. R. and D. H. Bromwich. 1987. The surface windfield over the Antarctic ice sheets. Nature, $328(6125), 51-54$.

Parker, D. E., C. K. Folland and M. Jackson. 1995. Marine surface temperature: observed variations and data requirements. Climatic Change, 31 (2-4), 559600 .

Robin, G. de Q. 1976. Reconciliation of temperature-depth profiles in polar ice sheets with past surface temperatures deduced from oxygen-isotope profiles. J. Glaciol., 16(74), 9-22.

Sampson, R. J. 1988. SURFACE III. Lawrence, KS, Interactive Concepts Inc.

Tabachnick, B. G. and L. S. Fidell. 1989. Using multivariate statistics. Second edition. New York, Harper Collins Publishers Inc.

Turner, J., T. A. Lachlan-Cope, J. P. Thomas and S. R. Colwell. 1995. The synoptic origins of precipitation over the Antarctic Peninsula. Antarct. Sci., 7(3), 327-337.

United States Navy. 1985. Sea ice climatic atlas. 1. Antarctic. Ashville, NC, U.S. Navy. Naval Oceanography Command Detachment.

Wendler, G., J. C. André, P. Pettré, J. Gosink and T. Parish. 1993. Katabatic winds in Adélie coast. In Bromwich, D. H. and C. R. Stearns, eds. Antarctic meteorology and climatology: studies based on automatic weather stations. Washington, DC, American Geophysical Union, 23-46. (Antarctic Research Series 61.)

Williams, R. B. G. 1986. Intermediate statistics. Second edition. London, Macmillan Education Ltd.

Zwally, H.J. and M. B. Giovinetto. 1997a. Annual sea level variability induced by changes in sea ice extent and accumulation on ice sheets: an assessment based on remotely sensed data. In Plag, H.-P. and S. Klosko, eds. Geophysical evidence of past and present climate change. Dordrecht, etc., Kluwer Academic Publishers, 327-340. (Surveys in Geophysics 18.)

Zwally, H. J. and M. B. Giovinetto. 1997b. Areal distribution of the oxygenisotope ratio in Greenland. Ann. Glaciol., 25, 208-213. 